\title{
Application of Intuitionistic Fuzzy Soft Matrices for Disease Diagnosis
}

\author{
Rana Muhammad Zulqarnain ${ }^{1}$, Muhammad Saeed ${ }^{2}$, Muhammad Irfan Ahamad ${ }^{3,}$, Sohaib Abdal $^{1}$, \\ Zeeshan Zafar ${ }^{3}$, Muhammad Aslam ${ }^{4}$ \\ ${ }^{1}$ School of Mathematics, Northwest University, Xi'an, China \\ ${ }^{2}$ School of Science, Department of Mathematics, University of Management and Technology, Lahore, Pakistan \\ ${ }^{3}$ College of Urban and Environmental Sciences, Northwest University, Xi' an, China \\ ${ }^{4}$ School of World History and Middle East Studies, Northwest University, Xian, China \\ Email address: \\ ranazulqarnain7777@gmail.com (R. M. Zulqarnain), muhammad.saeed@umt.edu.pk (M. Saeed), mirfan230@hotmail.com (M. I. Ahamad), \\ sohaib@stumail.nwu.edu.cn (S. Abdal), Zams706@live.com (Z. Zafar), aslammuhammad66nwu@outlook.com(M. Aslam) \\ ${ }^{*}$ Corresponding author
}

\section{To cite this article:}

Rana Muhammad Zulqarnain, Muhammad Saeed, Muhammad Irfan Ahamad, Sohaib Abdal, Zeeshan Zafar, Muhammad Aslam. Application of Intuitionistic Fuzzy Soft Matrices for Disease Diagnosis. International Journal of Discrete Mathematics. Vol. 5, No. 1, 2020 , pp. 4-9. doi: 10.11648/j.dmath.20200501.12

Received: August 27, 2020; Accepted: September 18, 2020; Published: September 30, 2020

\begin{abstract}
Decision Making is the best procedure to choose a superlative alternative from all feasible alternatives. Almost in all other issues, the overall number of criteria because decision making the general alternatives is pervasive. Nowadays decision making is a critical problem in every field of life. In some cases, we must deliberate membership unbiassed as the non- membership values for the suitable representation of an object in uncertain and indeterminate conditions that could not be handled by fuzzy sets nor by interval-valued fuzzy sets. To overcome these difficulties the notion of Intuitionistic fuzzy sets has been presented. In this paper, we study some basic concepts of fuzzy sets, soft sets, fuzzy soft sets, intuitionistic fuzzy sets, intuitionistic soft sets, intuitionistic fuzzy soft sets (IFSS), and intuitionistic fuzzy soft matrices (IFSM). Finally, in this research, we use the IFSM for disease diagnoses in patients who suffer from different diseases such as stomach ulcer and typhoid by using hypothetical data we conclude that patient $\mathrm{p}_{2}$ suffering stomach ulcer $\mathrm{p}_{2}$ and $\mathrm{p}_{3}$ patients suffering from typhoid.
\end{abstract}

Keywords: Fuzzy Set, Fuzzy Soft Set, Intuitionistic Soft Set, Intuitionistic Fuzzy Soft Set, Intuitionistic Fuzzy Soft Matrices

\section{Introduction}

Nowadays in every field of life, we face some uncertainties such as economics business, medical science, social science, etc. To handle these uncertainties different theories are presented like probability theory, fuzzy set, neutrosophic set, intuitionistic fuzzy set, rough set, etc. In 1999, Molodstov claimed that these theories have their challenges to overcome those challenges he proposed a new theory known as the soft set (SS) theory [1]. Many researchers used SS in decision making, medical diagnoses $[2,3]$. In 2001, Maji et al. developed a new theory which is known as the fuzzy soft set (FSS) theory by combining the fuzzy set and SS [4]. They also proposed some basic operations and properties such as intersection, union, complement, and De Morgan laws. They also reviewed the SS theory which was given by (Molodtsov 1999) and used this theory for decision making in 2002 [5]. Maji et al. introduced different types of SS with examples and defined some operations such as And-operation, Or-operation, union, intersection, complement, etc on SS [6].

Some limitations were faced in the work of (Maji et al. 2002) which were attensonoid by constructing a new definition of parameterization reduction and applied this definition in decision making. Ali et al. worked on SS theory and proposed some new definitions on SS such as restricted 
union, restricted intersection, etc, they also proved that the De-Morgan laws are held according to new definitions of SS theory [7]. A further contribution of Ahmad and Kharal in the properties of FSS which were defined in the work of $[4,9,10]$ with illustrations and counter illustrations and improved their work, they also extended the concept of FSS by defining some new definition such as the union of arbitrary FSS, the intersection of arbitrary FSS and proved De-Morgan inclusion on FSS [8]. Zulqarnain et al. used trapezoidal fuzzy numbers for disease identification [11]. The authors discussed FSS and constructed the fuzzy soft matrices with different properties and operations and used for decision making [12, 13]. Selim Eraslan studied the TOPSIS method on SS theory and used the newly developed method for decision making problems [14]. Zulqarnain et al also used the TOPSIS method for decision making by using SS [15-17]. The author's used the TOPSIS method for the prediction of diabetes patients in humans [18]. Many researchers studied the TOPSIS method on fuzzy sets and developed a fuzzy TOPSIS method and used this method for supplier selection, decision making, and medical diagnoses [19-22].

In 1984, Atanassov introduced intuitionistic fuzzy sets (IFS) with some basic operations and properties [23]. Many researchers studied IFS and used for decision making in different fields of life [24, 25]. Matrices play a very important role to solve our daily life problems such as decision making, medical and engineering, etc. but sometimes the classical matrices fail to resolve uncertain problems, to overcome these problems Chetia and Das developed the concept of IFSM with different operations and properties [26]. The authors developed a decision-making method known as the interval-valued fuzzy soft max-min decision-making method and used the interval-valued fuzzy soft matrices for decision making and medical diagnoses [2729]. They also compared the results obtained by fuzzy soft matrices and interval-valued fuzzy soft matrices [30]. Deli and Cagman constructed the Intuitionistic fuzzy parameterized soft sets with properties and developed different operations, finally, they used Intuitionistic fuzzy parameterized soft sets for decision making. The author's discussed IFS with the TOPSIS method and used the Intuitionistic fuzzy TOPSIS method for decision making and medical diagnoses [31, 32]. Dayan and Zulqarnain used the generalized fuzzy soft set for ranking of different students, they also developed generalized interval-valued fuzzy soft matrices [35, 36].

In this article, we discuss some basic definitions of fuzzy sets, SS, FSS, IFS, IFSS, and IFSM with basic operation. IFSM is used for disease diagnoses in those patients who suffer from different diseases by using hypothetical data.

\section{Preliminaries}

In this sequel, we study some basic concepts of fuzzy set, SS, FSS, and IFSS.

Definition 2.1 [33]

If we identify a set $\mathrm{A}$ in $\mathrm{X}$ by its membership function $\mu_{A}$ :
$X \rightarrow[0,1]$, then a set $A$ is called a fuzzy set.

Definition 2.2 [1]

Suppose $U$ be a universe set and $E$ be a set of values. Suppose $\mathrm{P}(\mathrm{U})$ indicates the power set of $\mathrm{Us} \mathrm{A} \leq \mathrm{E}$. A set $\left(F_{A}\right.$, E) known as $\mathrm{SS}$ Under $\mathrm{U}$ in which $F_{A}$ is processed by $F_{A}$ : $\mathrm{E} \rightarrow$ $\mathrm{P}(\mathrm{U})$ such as $F_{A}(\mathrm{e})=\varphi$ if e $\notin \mathrm{A}$.

Definition 2.3 [4]

$\chi_{A}$ be an FSS over U which is defined by a function $\mu_{A}$ which is represented by a mapping

" $\mu_{A}: \mathrm{E} \rightarrow \mathrm{F}(\mathrm{U})$ such that $\mu_{A}(\mathrm{t})=$ if $\mathrm{t} \notin \mathrm{A}$.

Where $\mu_{A}$ is called the fuzzy approximate function of FSS, and the value of $\mu_{A}(t)$ is a set called the element of FSS for all $\mathrm{t} \in \mathrm{E}$. This FSS can be represented in ordered pair form such as

$$
\chi_{A}=\left\{\left(\mathrm{t}, \mu_{A}(t)\right): \mathrm{t} \in \mathrm{E}, \mu_{A}(t) \in \mathrm{F}(\mathrm{U})\right\} .
$$

Example 2.4

$\mathrm{U}$ and $\mathrm{E}$ are the universe and set of attributes respectively.

$\mathrm{A}=\left\{\mathrm{t}_{1}, \mathrm{t}_{2}, \mathrm{t}_{3}\right\}$ is any subset of $\mathrm{E}$ than

$\mu_{A}\left(\mathrm{t}_{1}\right)=\left\{0.5 / \mathrm{P}_{1}, 0.3 / \mathrm{P}_{4}\right\}, \mu_{A}\left(\mathrm{t}_{2}\right)=\left\{0.2 / \mathrm{P}_{3}, 0.6 / \mathrm{P}_{4}, 0.3 / \mathrm{P}_{5}\right\}$ and $\mu_{A}\left(\mathrm{t}_{3}\right)=\mathrm{U}$, than SS $F_{A}$ is written as

$F_{A}=\left\{\left(\mathrm{t}_{1},\left\{0.5 / \mathrm{P}_{1}, 0.3 / \mathrm{P}_{4}\right\}\right),\left(\mathrm{t}_{2},\left\{0.2 / \mathrm{P}_{3}, 0.6 / \mathrm{P}_{4}, 0.3 / \mathrm{P}_{5}\right\}\right),\left(\mathrm{t}_{3}, \mathrm{U}\right)\right\}$

Note that FSS over U is denoted by FS (U).

Definition 2.5 [4]

Let $\chi_{A}, \chi_{B} \in \mathrm{FS}(\mathrm{U})$. Than $\chi_{A}$ is called a fuzzy soft subset of $\chi_{B}$, if $\mu_{A}(\mathrm{t})$ is a subset of $\mu_{B}(\mathrm{t})$ for all $\mathrm{t} \in \mathrm{E}$., it is denoted as $\chi_{A} \subseteq \chi_{B}$.

Example 2.6

$\mathrm{U}$ and $\mathrm{E}$ are the universe and set of attributes respectively. $A=\left\{\mathrm{t}_{1}, \mathrm{t}_{2}, \mathrm{t}_{3}\right\}$ is any subset of $\mathrm{E}$ than

$\mu_{A}\left(\mathrm{t}_{1}\right)=\left\{0.5 / \mathrm{P}_{1}, 0.3 / \mathrm{P}_{4}\right\}, \mu_{A}\left(\mathrm{t}_{2}\right)=\left\{0.2 / \mathrm{P}_{3}, 0.6 / \mathrm{P}_{4}, 0.3 / \mathrm{P}_{5}\right\}$ and $\mu_{A}\left(\mathrm{t}_{3}\right)=\mathrm{U}$, than $\mathrm{SS} F_{A}$ is written as

$F_{A}=\left\{\left(\mathrm{t}_{1},\left\{0.5 / \mathrm{P}_{1}, 0.3 / \mathrm{P}_{4}\right\}\right),\left(\mathrm{t}_{2},\left\{0.2 / \mathrm{P}_{3}, 0.6 / \mathrm{P}_{4}, 0.3 / \mathrm{P}_{5}\right\}\right),\left(\mathrm{t}_{3}, \mathrm{U}\right)\right\}$

Note that FSS over U is denoted by FS (U).

Definition 2.7 [12]

A pair $(F, A)$ is called FSS in the fuzzy soft class (M, E). Then $(\mathrm{F}, \mathrm{A})$ is represented in a matrix form such as

$A_{m \times n}=\left[a_{i j}\right]_{m \times n}$, where

$$
a_{i j}=\left\{\begin{array}{c}
\mu_{j}\left(y_{j}\right) \text { if } y_{j} \in A \\
0 \text { if } y_{j} \notin A
\end{array}\right.
$$

Definition 2.8 [23]

IFS $A$ in a finite set $X$ can be written as

$A=\left\{x, \mu_{a}(x), v_{A}(x): x \in X\right\}$, where

$\mu_{a}(x), v_{A}(x): X \rightarrow[0,1]$ are membership and nonmembership functions respectively, such that

$$
0 \leq \mu_{a}(x)+v_{A}(x) \leq 1 .
$$

Definition 2.9 [34]

Suppose $\mathrm{S}$ be a universal set and $\mathrm{N}$ be a collection of parameters suppose $\leq \mathrm{N}$ then a set $(\mathrm{F}$, ) is called IFSS over $\mathrm{S}$. Where $\mathrm{F}$ is a mapping from $\mathrm{F}: \rightarrow \hat{\mathrm{I}}$ where $\hat{\mathrm{I}}$ is the collection of all intuitionistic soft set. 


\section{Definition 2.10 [26]}

Suppose $\mathrm{S}$ and $\mathrm{N}$ are universal set and set of parameters respectively and $\leq \mathrm{N}$ and $\left(\mathrm{F}_{A}, \mathrm{~N}\right)$ be an IFSS over $\mathrm{S}$. Than any subset of $\mathrm{S} \times \mathrm{N}$ is defined as follows $R_{A}=\{(s, n) \in$ $\left.\mathrm{F}_{A}(n)\right\}$. The membership function and non-membership function of this relation can be written as follows

$\mu_{R_{A}}: \mathrm{S} \times \mathrm{N} \rightarrow[0,1]$ and $R_{A}: \mathrm{S} \times \mathrm{N} \rightarrow[0,1]$, where $\mu_{R_{A}}(\mathrm{~s}$, n) $\in[0,1]$ and $R_{A}(\mathrm{~s}, \mathrm{n}) \in[0,1]$.

If $\left(\mu_{i j}, \mu_{i j}\right)=\mu_{R_{A}}\left(s_{i}, n_{j}\right), R_{A}\left(s_{i}, n_{j}\right)$, then it can be written in matrix form as follows

$$
\left[\mu_{i j}, \mu_{i j}\right]_{m \times n}=\left[\begin{array}{cccc}
\left(\mu_{11}, \mu_{11}\right) & \left(\mu_{12}, \mu_{12}\right) & \ldots & \left(\mu_{1 n}, \mu_{1 n}\right) \\
\left(\mu_{21}, \mu_{21}\right) & \left(\mu_{22}, \mu_{22}\right) & \ldots & \left(\mu_{2 n}, \mu_{2 n}\right) \\
\vdots & \vdots & \vdots & \vdots \\
\left(\mu_{m 1}, \mu_{m 1}\right) & \left(\mu_{m 2}, \mu_{m 2}\right) & \ldots & \left(\mu_{m n}, \mu_{m n}\right)
\end{array}\right]
$$

Definition 2.11 [26]

Assume $\mathrm{S}=\left[a_{i j}\right]_{m \times n}$ and $\mathrm{T}=\left[b_{i j}\right]_{n \times p}$ are two IFSM, then their product is defined as follows

$\mathrm{S} * \mathrm{~T}=\left[c_{i k}\right]_{m \times p}=\left\{\max -\min \left(\mu_{S_{i}}, \mu_{T_{j}}\right), \min -\max \left(S_{i}, T_{j}\right)\right\}$ for all $\mathrm{i}, \mathrm{j}$.

\section{Effect of Stomach Ulcer and Typhoid in Medical Analysis}

In this section, we study the different climates and environmental features causing several diseases. For the diagnosis of these diseases, several antibiotics and drugs are available. The stomach ulcer is caused by food poisoning and affects the different organs of our body such as the digestive system. The stomach plays a vital role in the second phase of the digestive system, it performs a chemical breakdown in humans and other animals due to enzymes and hydrochloric acid. Typhoid is a bacterial infection and caused by Salmonella typhi bacteria it is very dangerous for children especially in developing countries and affects almost 26 million peoples every year. In this research, we used intuitionistic fuzzy soft matrices for diagnoses of those people who are suffering from stomach ulcers and typhoid.

IFSM in Medical Analysis

Assume $\mathrm{S}$ be a set of symptoms of stomach ulcer and typhoid, D is the side effects of diseases associated to these signs, and $\mathrm{P}$ be a set of patients characterized the set of signs presenting in the set $\mathrm{S}$, we can get an FSS $\left(F_{A}, \mathrm{D}\right)$ over $\mathrm{S}$. Relation matrix $A$ gets from the FSS $\left(F_{A}, \mathrm{D}\right)$. we assign the matrix as symptoms diseases matrix. The complement of above $\mathrm{FSS}\left(F_{A}, \mathrm{D}\right)^{c}$ is also gives a relation matrix $A^{c}$ which is known as no symptoms disease matrix. Similarly, we develop another $\mathrm{FSS}\left(F_{B}, \mathrm{~S}\right)$ over $\mathrm{P}$ which provides us, patients, disease signs relation matrix represented by $\mathrm{B}$ and its complement $\left(F_{B}, \mathrm{~S}\right)^{c}$ gives the non symptoms relation matrix $B^{c}$. Now we get two new relation matrices $M_{1}=B \cdot A$ and $M_{2}=B \cdot A^{c}$ known as symptoms patient disease and patient symptoms nondisease matrix appropriately. In the same way, we get the relation matrix $M_{3}=B^{c} \cdot A$ and $M_{4}=B^{c} \cdot A^{c}$ known the patient non-symptoms disease matrix and patient non-symptoms nondisease matrix respectively. Now

$$
\begin{aligned}
& M_{1}=B \cdot A, M_{2}=B \cdot A^{c} \\
& M_{3}=B^{c} \cdot A, M_{4}=B^{c} \cdot A^{c}
\end{aligned}
$$

and use definition membership value

$$
\mathrm{ZV}\left(M_{1}\right), \mathrm{ZV}\left(M_{2}\right), \mathrm{ZV}\left(M_{3}\right), \mathrm{ZV}\left(M_{4}\right),
$$

We compute the diagnosis score $\left(S_{M_{1}}\right)$ and $\left(S_{M_{2}}\right)$ for and against the diseases appropriately like

$$
\begin{gathered}
\left(S_{M_{1}}\right)=\left[\rho\left(M_{1}\right) \mathrm{kl}\right]_{p \times q}, \text { where } \rho\left(M_{1}\right) \mathrm{kl}=\delta\left(M_{1}\right) \mathrm{kl}-\delta\left(M_{3}\right) \mathrm{kl} \\
\operatorname{an}( \\
\left(S_{M_{2}}\right)=\left[\rho\left(M_{2}\right) \mathrm{kl}\right]_{p \times q}, \text { where } \rho\left(M_{2}\right) \mathrm{kl}=\delta\left(M_{2}\right) \mathrm{kl}-\delta\left(M_{4}\right) \mathrm{kl}
\end{gathered}
$$

Then if $\max \left(S_{M_{1}}\left(p_{i}, d_{j}\right)-S_{M_{2}}\left(p_{i}, d_{k}\right)\right.$ appear for exactly $\left(p_{i}, d_{k}\right)$ only.

Now we would be able to accept that diagnosis hypothesis for patient $P_{i}$ is the disease $d_{k}$. Then in this way, there is a connection in which the hypothesis is repeated for patient $p_{i}$ by assuming the symptoms.

\section{Application of IFSM in Medical Diagnoses}

Suppose $P=\left\{P_{1}, P_{2}, P_{3}\right\}$ are three patients who are suffering from a disease whose symptoms are fever, flu, the digestive problem represented as $S=\left\{s_{1}, s_{2}, s_{3}\right\}$ and the possible diseases related to the above symptoms may be stomach ulcer and typhoid represented by $\mathrm{D}=\left\{d_{1}, d_{2}\right\}$. Let the FSS (F, D) over S, where is a mapping such that F: $\mathrm{D} \rightarrow \mathrm{F}(\mathrm{S})$, gives an approximation result of two disease and their symptoms.

$$
\left(F_{A}, D\right)=\left\{F_{A}\left(d_{1}\right)=\left\{\left(n_{1}, 0.7,0.2\right),\left(n_{2}, 0.4,0.5\right),\left(n_{3}, 0.5,0.3\right)\right\},\left\{F_{A}\left(d_{2}\right)=\left\{\left(n_{1}, 0.5,0.3\right),\left(n_{2}, 0.3,0.6\right),\left(n_{3}, 0.6,0.2\right)\right\}\right\}\right.
$$

The complement of $\left(F_{A}, D\right)$ is

$$
\left(F_{A}, D\right)^{c}=\left\{F_{A}\left(d_{1}\right)^{c}=\left\{\left(n_{1}, 0.8,0.7\right),\left(n_{2}, 0.5,0.4\right),\left(n_{3}, 0.7,0.5\right)\right\},\left\{F_{A}\left(d_{2}\right)^{c}=\left\{\left(n_{1}, 0.7,0.5\right),\left(n_{2}, 0.4,0.3\right),\left(n_{3}, 0.8,0.6\right)\right\}\right\}\right.
$$

We are representing the $\operatorname{FSS}\left(F_{A}, D\right)$ and its complement $\left(F_{A}, D\right)^{c}$ in matrix form can be written as follows

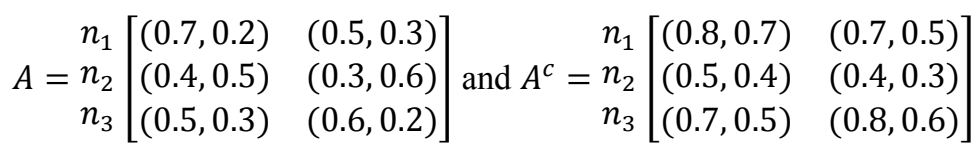


Let $P=\left\{P_{1}, P_{2}, P_{3}\right\}$ be a set of patients and $S=\left\{s_{1}, s_{2}, s_{3}\right\}$ be a set of symptoms. Than $\left(F_{B}, S\right)$, where $F_{B}$ is a mapping such that $F_{B}: \mathrm{S} \rightarrow \mathrm{F}(\mathrm{P})$ gives the collection of patients and their symptoms.

$$
\begin{gathered}
\left(F_{B}, S\right)=\left\{F_{B}\left(n_{1}\right)=\left\{\left(p_{1}, 0.6,0.3\right),\left(p_{2}, 0.7,0.2\right),\left(p_{3}, 0.5,0.4\right)\right\}, F_{B}\left(n_{2}\right)=\left\{\left(p_{1}, 0.3,0.6\right),\left(p_{2}, 0.4,0.5\right),\left(p_{3}, 0.2,0.7\right)\right\},\right. \\
\left.F_{B}\left(n_{3}\right)=\left\{\left(p_{1}, 0.5,0.4\right),\left(p_{2}, 0.6,0.2\right),\left(p_{3}, 0.6,0.3\right)\right\}\right\}
\end{gathered}
$$

The complement of $\left(F_{B}, S\right)$ is

$$
\begin{aligned}
& \left(F_{B}, S\right)^{c}=\left\{F_{B}\left(n_{1}\right)^{c}=\left\{\left(p_{1}, 0.7,0.6\right),\left(p_{2}, 0.8,0.7\right),\left(p_{3}, 0.6,0.5\right)\right\}, F_{B}\left(n_{2}\right)=\left\{\left(p_{1}, 0.4,0.3\right),\left(p_{2}, 0.5,0.4\right),\left(p_{3}, 0.3,0.2\right)\right\},\right. \\
& \left.F_{B}\left(n_{3}\right)=\left\{\left(p_{1}, 0.6,0.5\right),\left(p_{2}, 0.8,0.6\right),\left(p_{3}, 0.7,0.6\right)\right\}\right\}
\end{aligned}
$$

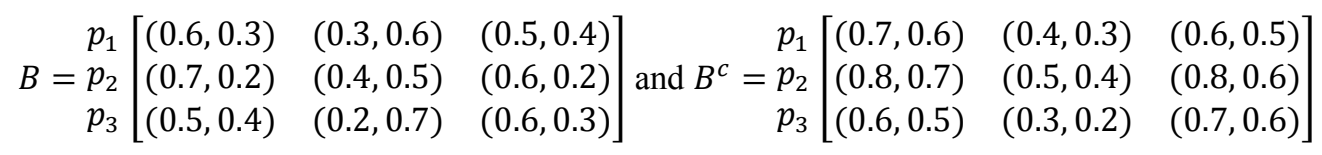

Where $B$ and $B^{c}$ represents the symptoms and non-symptoms patient matrix.

Thus we can get

$$
M_{1}=B \cdot A=\left[\begin{array}{lll}
(0.6,0.3) & (0.3,0.6) & (0.5,0.4) \\
(0.7,0.2) & (0.4,0.5) & (0.6,0.2) \\
(0.5,0.4) & (0.2,0.7) & (0.6,0.3)
\end{array}\right]\left[\begin{array}{ll}
(0.7,0.2) & (0.5,0.3) \\
(0.4,0.5) & (0.3,0.6) \\
(0.5,0.3) & (0.6,0.2)
\end{array}\right]
$$

By using definition 1.11 we get

$$
M_{1}=B \cdot A=\begin{array}{r}
p_{1} \\
p_{2} \\
p_{3}
\end{array}\left[\begin{array}{ll}
(0.6,0.3) & (0.5,0.3) \\
(0.7,0.2) & (0.6,0.2) \\
(0.5,0.3) & (0.6,0.3)
\end{array}\right]
$$

Similarly, we can get

$$
\begin{aligned}
& M_{2}=B \cdot A^{c}=\begin{array}{r}
p_{1} \\
p_{2} \\
p_{3}
\end{array}\left[\begin{array}{ll}
(0.6,0.5) & (0.6,0.5) \\
(0.7,0.5) & (0.7,0.5) \\
(0.6,0.5) & (0.6,0.5)
\end{array}\right] \\
& M_{3}=B^{c} \cdot A=p_{1}\left[\begin{array}{ll}
(0.7,0.5) & (0.6,0.5) \\
p_{2} & p_{3} \\
(0.7,0.5) & (0.6,0.6) \\
(0.6,0.5) & (0.6,0.5)
\end{array}\right]
\end{aligned}
$$

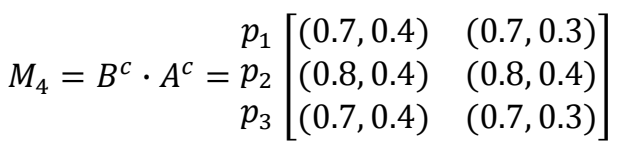

The membership of $M_{1}, M_{2}, M_{3}$ and $M_{4}$ is $\mathrm{ZV}\left(M_{1}\right), \mathrm{ZV}\left(M_{2}\right), \mathrm{ZV}\left(M_{3}\right), \mathrm{ZV}\left(M_{4}\right)$ respectively

$$
\begin{array}{r}
p_{1}\left[\begin{array}{ll}
(0.6-0.3) & (0.5-0.3) \\
\mathrm{ZV}\left(M_{1}\right)=p_{2} \\
p_{3}
\end{array}\left[\begin{array}{ll}
(0.7-0.2) & (0.6-0.2) \\
(0.5-0.3) & (0.6-0.3)
\end{array}\right]=\left[\begin{array}{ll}
0.3 & 0.2 \\
0.5 & 0.4 \\
0.2 & 0.3
\end{array}\right]\right. \\
p_{1}\left[\begin{array}{ll}
(0.6-0.5) & (0.6-0.5) \\
\mathrm{ZV}\left(M_{2}\right)=p_{2} \\
p_{3} \\
(0.7-0.5) & (0.7-0.5) \\
(0.6-0.5) & (0.6-0.5)
\end{array}\right]=\left[\begin{array}{ll}
0.1 & 0.1 \\
0.2 & 0.2 \\
0.1 & 0.1
\end{array}\right] \\
p_{1}\left[\begin{array}{ll}
(0.7-0.5) & (0.6-0.5) \\
\mathrm{ZV}\left(M_{3}\right)=p_{2} \\
p_{3} \\
(0.7-0.5) & (0.6-0.6) \\
(0.6-0.5) & (0.6-0.5)
\end{array}\right]=\left[\begin{array}{ll}
0.2 & 0.1 \\
0.2 & 0.0 \\
0.1 & 0.1
\end{array}\right] \\
p_{1}\left[\begin{array}{ll}
(0.7-0.4) & (0.7-0.3) \\
\mathrm{ZV}\left(M_{4}\right)=p_{2} \\
p_{3} \\
(0.8-0.4) & (0.8-0.4) \\
(0.7-0.4) & (0.7-0.3)
\end{array}\right]=\left[\begin{array}{ll}
0.3 & 0.4 \\
0.4 & 0.4 \\
0.3 & 0.4
\end{array}\right]
\end{array}
$$




$$
\begin{aligned}
& \begin{array}{r}
p_{1} \\
S_{M_{1}}=\mathrm{ZV}\left(M_{1}\right)-\mathrm{ZV}\left(M_{3}\right)=p_{2} \\
p_{3}
\end{array}\left[\begin{array}{ll}
0.3-0.2 & 0.2-0.1 \\
0.5-0.2 & 0.4-0.0 \\
0.2-0.1 & 0.3-0.1
\end{array}\right]=p_{1} p_{2}\left[\begin{array}{cc}
0.1 & 0.1 \\
p_{3}
\end{array}\left[\begin{array}{cc}
0.3 & 0.4 \\
0.1 & 0.2
\end{array}\right]\right.
\end{aligned}
$$

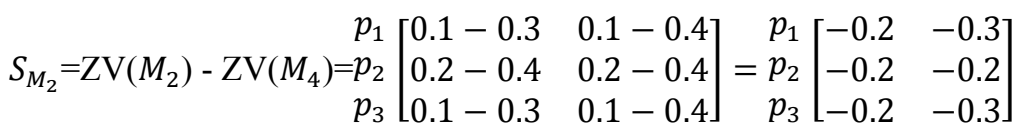

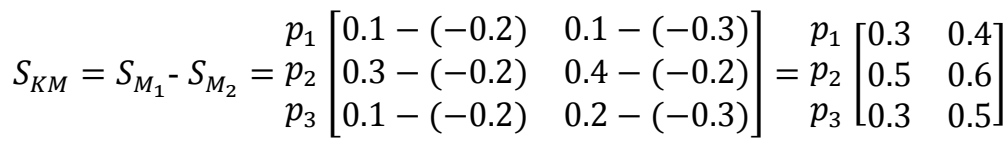

Table 1. Ranking of Patients with disease.

\begin{tabular}{lll}
\hline $\boldsymbol{S}_{\boldsymbol{K} M}$ & $\boldsymbol{d}_{\mathbf{1}}$ & $\boldsymbol{d}_{\mathbf{2}}$ \\
\hline$p_{1}$ & 0.3 & 0.4 \\
$p_{2}$ & 0.7 & 0.6 \\
$p_{3}$ & 0.2 & 0.4 \\
\hline
\end{tabular}

\section{Conclusion}

In this article, we discuss some basic definitions of fuzzy sets, soft set, fuzzy soft set, Intuitionistic fuzzy set, Intuitionistic fuzzy soft set, and IFSM with some basic operation. We use the IFSM for disease diagnoses in patients who suffer from different diseases such as stomach ulcers and typhoid by using hypothetical data. We consider three patients who are suffering from a disease stomach ulcer or typhoid whose symptoms are fever, flu, the digestive problem. Finally, by using intuitionistic fuzzy soft matrix we conclude that patient $p_{2}$ suffering stomach ulcer $p_{1}$ and $p_{3}$ patients suffering from disease typhoid. In the future, we extend this technique for decision making in the neutrosophic set, interval neutrosophic set, neutrosophic soft set, and interval neutrosophic soft set, etc.

\section{References}

[1] Molodtsov D (1999) Soft Set Theory First Results. Computers \& Mathematics with Applications 37: 19-31.

[2] Dauda MK, Mamat M, Waziri MY (2015) AN APPLICATION OF SOFT SET IN DECISION. Jurnal Teknologi: 119-122.

[3] Yuksel S, Dizman TH, Yildizdan G, Sert U (2013) Application of soft sets to diagnose the prostate cancer risk. Journal of Inequalities and Applications: 1-16.

[4] Maji PK, Biswas R, Roy AR (2001) Fuzzy soft sets. Journal of Fuzzy Mathematics 9 (3): 589-602.

[5] Maji PK, Roy AR, Biswas R (2002) An Application of Soft Sets in A Decision Making Problem. Computers and Mathematics with Applications 44: 1077-1083.

[6] Maji PK, Biswas R, Roy AR (2003) Soft set theory. Comput Math Appl 45: 555-562.

[7] Ali MI, Feng F, Liu X, Min WK, Shabir M (2009) On some new operations in soft set theory. Computers and Mathematics with Applications 57 (9): 1547-1553.

[8] Ahmad B, Kharal A (2009) On Fuzzy Soft Sets. Advances in Fuzzy Systems: 1-6.
[9] Roy AR, Maji PK (2007) A fuzzy soft set theoretic approach to decision making problems. Journal of Computational and Applied Mathematics 203: 412-418.

[10] Yang X, Yu D, Yang J, Wu C (2007) Generalization of Soft Set Theory: From Crisp to Fuzzy Case. Fuzzy Information and Engineering: $345-354$.

[11] Zulqarnain RM, Xin XL, Ali B, Abdal S, Maalik A, Ali L, Ahamad MI, Zafar Z (2020) Disease identification using trapezoidal fuzzy numbers by Sanchez's approach. International Journal of Pharmaceutical Sciences and Review Research 61 (1): 13-18.

[12] Borah MJ, Neog TJ, Sut DK (2012) Fuzzy Soft Matrix Theory And Its Decision Making. International Journal of Modern Engineering Research 2 (2): 121-127.

[13] Cagman N, Enginoğlu S (2012) Fuzzy soft matrix theory and its application in decision making. Iranian Journal of Fuzzy Systems 9 (1): 109-119.

[14] Eraslan S (2015) A Decision Making Method via TOPSIS on Soft Sets. Journal of New Results in Science. 8: 57-71.

[15] Zulqarnain RM, Abdal S, Maalik A, Ali B, Zafar Z, Ahamad MI, Younas S, Mariam A, Dayan F (2020) Application of TOPSIS Method in Decision Making Via Soft Set. BIOMEDICAL Journal of Scientific \& Technical Research 24 (3): 18208-18215.

[16] Zulqarnain RM, Saeed M, Ahmad N, Dayan F, Ahmad B (2020) Application of TOPSIS Method for Decision Making. International Journal of Scientific Research in Mathematical and Statistical Sciences 7 (2): 76-81.

[17] Zulqarnain RM, Xin XL, Saeed M, Ahmad N, Dayan F, Ahmad B (2020) Recruitment of Medical Staff in Health Department by Using TOPSIS Method. International Journal of Pharmaceutical Sciences and Review Research 62 (01): 1-7.

[18] Zulqarnain M, Dayan F, Saeed M (2018) TOPSIS Analysis for The Prediction of Diabetes Based on General Characteristics of Humans. International Journal of Pharmaceutical Sciences and Research 9 (7): 2932-2938.

[19] Kacprzak D (2018) Fuzzy topsis method for group decision making. Multiple Criteria Decision Making 13: 116-132.

[20] Sevkli M, Zaim S, Turkyılmaz A, Satır M (2010) An Application of Fuzzy Topsis Method for Supplier Selection. IEEE International Conference on Fuzzy Systems (July).

[21] Zulqarnain RM, Abdal S, Ali B, Ali L, Dayan F, Ahamad MI, Zafar Z (2020) Selection of Medical Clinic for Disease Diagnosis by Using TOPSIS Method. International Journal of Pharmaceutical Sciences and Review Research 61 (1): 22-27. 
[22] Zulqarnain M, Dayan F (2017) Choose Best Criteria for Decision Making Via Fuzzy Topsis Method. Mathematics and Computer Science 2 (6): 113-118.

[23] Atanassov T. (1986) Intultionistic Fuzzy Sets. Fuzzy Sets and Systems 20: 87-96.

[24] Arora HD, Kumar V (2019) A Decision-making Problem as an Applications of Intuitionistic Fuzzy Set 2: 5259-5261.

[25] Dymova L, Izabela R, Sevastjanov P (2008) A New Method for Decision Making in the Intuitionistic Fuzzy Setting. Springer-Verlag Berlin Heidelberg: 229-240.

[26] Chetia B, Das PK (2012) Some results of intuitionistic fuzzy soft matrix theory. Advances in Applied Science Research 3: 412-423.

[27] Zulqarnain M, Saeed M (2017) A New Decision Making Method on Interval Valued Fuzzy Soft Matrix (IVFSM). British Journal of Mathematics \& Computer Science 20 (5): $1-17$.

[28] Zulqarnain M, Saeed M (2016) An Application of Interval Valued Fuzzy Soft Matrix in Decision Making Problem. Science International (Lahore) 28 (3): 2261-2264.

[29] Zulqarnain RM, Xin XL, Saeed M, Ahmad N, Dayan F, Ahmad B (2020) Application of Interval Valued Fuzzy Soft Max-Min Decision Making Method in Medical Diagnosis. International Journal of Pharmaceutical Sciences and Review Research 62 (1): 56-60.
[30] Zulqarnain M, Saeed M, Tabassum MF (2016) Comparison between Fuzzy Soft Matrix (FSM) and Interval Valued Fuzzy Soft Matrix (IVFSM) in Decision Making. Science International (Lahore) 28 (5): 4277-4283.

[31] Yinghui W, Wenlu L (2015) The Application of Intuitionistic Fuzzy Set TOPSIS Method in Employee Performance Appraisal. International Journal of u- and e- Service, Science and Technology 8 (3): 329-44.

[32] Zulqarnain M, Dayan F (2017) Selection Of Best Alternative For An Automotive Company By Intuitionistic Fuzzy TOPSIS Method. International Journal of Scientific \& Technology Research 6 (10): 126-132.

[33] Zadeh LA (1965) Fuzzy Sets. Information and Control 8: 338 353.

[34] Yong J X, Yong K S, Deng F L (2010) Intuitionistic Fuzzy Soft Set. IEEE International Conference on Fuzzy Systems: 1-4.

[35] Dayan F, Zulqarnain M, Hassan N (2017) A Ranking Method for Students of Different Socio Economic Backgrounds Based on Generalized Fuzzy Soft Sets. International Journal of Science and Research (IJSR) 6 (9): 691-694.

[36] Dayan F, Zulqarnain M (2018) On Generalized Interval Valued Fuzzy Soft Matrices. American Journal of Mathematical and Computer Modelling 3 (1): 1-9. 